
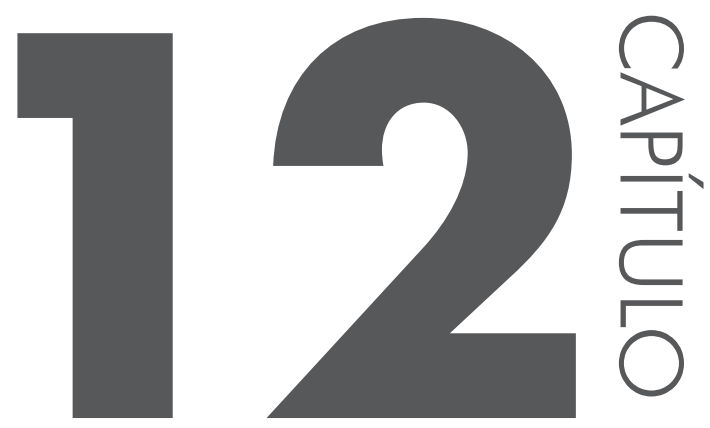

\title{
REDES SOCIAIS E A POLÍCIA COMUNITÁRIA: ESTUDO DE CASO DOS CONSEGS DO VALE DO ARARANGUÁ'
}

Márcio Giani Rosa de Matos Márcio Vieira de Souza

\section{INTRODUC̣ÃO}

A busca por segurança foi um dos motores que levaram os homens a viverem em grupos, ou seja, a segurança tem papel significativo na formação da vida em sociedade.

1 Este estudo é baseado no trabalho de conclusão de curso especialização em Tecnologias da Informação e Comunicação Aplicadas à Segurança Pública e Direitos Humanos da Universidade Federal de Santa Catarina, de autoria de Marcio Giani Rosa de Matos e orientado pelo Prof. Dr. Marcio Vieira de Souza. 
Viver em sociedade - pequenos grupos - gerava proteção contra algum inimigo externo, contudo, exigiam que certas regras, necessárias à sobrevivência do grupo, fossem observadas. Alguns componentes do grupo receberam a competência para policiar o cumprimento das regras sociais. Nascia ali o embrião do que hoje chamamos de Polícia (MARCINEIRO; PACHECO, 2005).

A polícia, ao longo do tempo, desempenhou seu papel das mais variadas formas. Durante sua evolução, o ato de policiar foi influenciado por diversas ideologias de polícia, dentre as quais se podem destacar: Ideologia Militarista, Ideologia de Controle Social, Ideologia Reativa e Ideologia Preventiva.

Baseados nas ideologias de polícia, nas condições de seus Estados e em suas culturas, os países desenvolveram diversos modelos de polícia, cada um com suas características: modelo anglo-saxão de polícia (descentralizado), modelo francês (Maréchaussée - militar), modelo português (influenciado pelo francês) e modelo oriental (proativo).

O modelo oriental é o único baseado na Ideologia Preventiva, ou seja;

na escola oriental, o trabalho das agências de preservação da ordem pública é centrado no tratamento proativo do crime, agindo sobre os elementos que possibilitam a prática do crime, quais sejam: um ambiente apropriado para a prática do crime, um agente disposto a praticar tal crime e uma vítima em potencial. (MARCINEIRO, 2005, p. 39)

O Brasil, devido ao fato de ter sido colônia portuguesa, iniciou sua polícia na Ideologia Militarista com um modelo herdado dos franceses. Contudo, ao logo da sua evolução, todos os modelos de polícia apresentados anteriormente influenciaram a polícia brasileira, cada qual com mais ou menos intensidade em diferentes períodos da história.

Todavia, estes modelos não se mostraram eficientes para resolver o crescente problema do crime e da violência, que apresenta índices cada vez mais elevados, contando com criminosos cada vez mais cruéis, atuantes e impunes. Soma-se ao aumento do crime e da violência as mudanças democráticas estabelecidas com a Constituição Federal de 1988, que exigiu das polícias uma nova postura e uma ruptura com os antigos paradigmas da segurança pública.

A busca por respostas ao problema do crime e da violência, bem como a busca por adequar as polícias a um modelo democrático, levaram as polícias do Brasil a uma visão mais ampla dos problemas da Segurança Pública e, consequentemente, ao encontro da Filosofia de Polícia Comunitária, na qual todos são corresponsáveis.

O Brasil seguiu, assim, o mesmo caminho que trilharam Estados Unidos da América, Japão, Canadá, Espanha e outros países, que encontraram na democratização das polícias a solução para inúmeros problemas de segurança pública. 
A função da polícia dentro da Filosofia Comunitária vai muito além de defender os interesses do Estado por meio do controle social como modelo latino-francês, ou de patrulhar as ruas e controlar o crime atendendo às chamadas de emergência e prendendo criminosos, tal qual o modelo anglo-saxão. Nela, deve-se buscar a prevenção do crime, estabelecendo parcerias com a comunidade, identificando problemas e agregando recursos da polícia, Estado e comunidade na resolução destes.

O caminho democrático levou o Brasil, no ano 2000, a implantar o Plano Nacional de Segurança Pública (PNSP), considerado a primeira política nacional e democrática de segurança do Brasil, seguido em 2007 pelo Programa Nacional de Segurança Pública com Cidadania (Pronasci), que alavancou a participação da sociedade na elaboração das políticas públicas voltadas à segurança.

Em Santa Catarina, bem como em diversos outros estados do Brasil, no encalço da participação da sociedade nos problemas de segurança, e motivados por incentivos da Secretária Nacional de Segurança Pública (Senasp), vem sendo, paulatinamente, implementada a Filosofia de Polícia Comunitária.

A principal ferramenta utilizada pelas polícias na Filosofia de Polícia Comunitária para estabelecer parceria com as comunidades e agirem juntas na solução de problemas são os Conselhos Comunitários de Segurança (Conseg).

A Senasp (2007) define os Consegs como:

Entidade de direito privado, com vida própria e independente em relação aos segmentos da segurança pública ou a qualquer outro órgão público; modalidade de associação comunitária, de utilidade pública, sem fins lucrativos, constituída no exercício do direito de associação garantido no art. $5^{\circ}$, inciso XVII, da Constituição Federal, e que tem por objetivos mobilizar e congregar forças da comunidade para a discussão de problemas locais da segurança pública, no contexto municipal ou em subdivisão territorial de um município (SENASP, 2007, p. 297).

\section{OS CONSEGS E AS REDES SOCIAIS}

O Conseg, em Santa Catarina, é o principal meio pelo qual se busca instituir uma polícia democrática e cidadã, ou seja, é a principal ferramenta da Filosofia de Polícia Comunitária. Marcineiro (2009) destaca que para alcançar os objetivos da Filosofia de Polícia Comunitária é preciso que as pessoas que compõem aquela comunidade reúnam-se com os policiais, seja nos Consegs ou em qualquer outra forma de reunir pessoas para discutir soluções para os problemas de segurança pública, inerentes àquela comunidade.

Por sua estruturação, podemos afirmar que os conselhos, por meio de seus conselheiros - cidadãos, polícia, empresas, Poder Legislativo etc. -, que se 
relacionam e conectam-se, constituem uma rede social compartilhando o objetivo comum de trocar e gerar informações sobre segurança pública. Destaca-se que as redes sociais são um dos principais meios que a sociedade dispõe para o compartilhamento da informação e do conhecimento e consequente solução de problemas, valendo-se das relações existentes entre seus integrantes (MARTINS; LOTTA, 2010).

As redes sociais são, sem dúvida, mecanismos poderosos com potencial para viabilizar a participação democrática do povo na administração do Estado. E os Consegs, enquanto rede social, teoricamente são uma ferramenta fantástica para a efetivação da participação da comunidade nos assuntos de segurança a ela relativos. Contudo, na prática, os Consegs da microrregião de Araranguá (Vale do Araranguá) não desempenham seus papéis satisfatoriamente.

Entrevistas feitas com conselheiros e coordenadores dos Consegs do Vale do Araranguá revelaram sérios problemas que afetam o desempenho dos conselhos:

- Baixo número de conselheiros e representatividade: mesmo com os esforços e os apelos das polícias, os Consegs não cooptam pessoas suficientes para que os conselhos sejam órgão representativo da vontade da comunidade.

- Dificuldade de divulgar sua filosofia e ações.

- Curto ciclo de vida: após ações voltadas para estimular as comunidades à formação dos seus conselhos, os Consegs nascem atuantes e participativos, contudo, aos poucos - em alguns casos, rapidamente - as reuniões mensais se esvaziam e os conselhos sucumbem.;

- Interesses distintos da segurança: os conselheiros relataram que muitos se aproximam dos Consegs com objetivo de se autopromoverem, com o intuito de galgar vantagens pessoais e políticas.

- Descrédito: são poucos os conselheiros que ainda acreditam que os Consegs são meios eficientes à Filosofia de Polícia Comunitária.

- Distanciamento das TIC: os Consegs não utilizam, ou utilizam parcamente, as TIC como ferramentas auxiliadoras ao cumprimento dos seus objetivos. Apenas um, dentre todos os conselhos, possuía um blog; nos outros nem mesmo o e-mail era utilizado.

Tendo como base os problemas expostos, os questionários de pesquisa foram confeccionados. Algumas das questões visavam encontrar as causas e outras possibilitariam a sugestões de possíveis soluções. Mas antes de relatarmos as considerações galgadas a partir das respostas dos participantes, faz-se necessário ressaltar outros dois problemas que a análise dos questionários rutilou:

- Ausência de jovens: os conselhos não contam com a participação de jovens com menos de 25 anos de idade. 
- Discrepância entre os gêneros: os participantes do sexo masculino são a maioria absoluta.

Uma vez que os problemas relativos aos Consegs estão elencados, passa-se à análise dos dados quantitativos e qualitativos, na busca de causas e soluções.

Os questionários aplicados aos conselheiros e não conselheiros foram distintos. O grupo dos não conselheiros foi dividido em três subgrupos: pedestres sem nenhum contato com a Filosofia de Polícia Comunitária, trabalhadores do comércio que participam de um projeto embasado nesta filosofia há um ano, e diretores de escolas que participam de projetos comunitários há dois anos. A divisão em grupos e subgrupos permitiu o cruzamento de dados, que levou às conclusões e considerações acerca dos problemas apresentados.

Comparando o número de não conselheiros conhecedores da Filosofia de Polícia Comunitária e dos Consegs com o número de conselheiros por faixa etária, pode-se constatar que os percentuais são praticamente os mesmos. Entre os mais jovens, o percentual de não conselheiros conhecedores da Filosofia fica próximo de zero, oscila entre aqueles com idade entre 25 e 45 anos e tem seu ápice naqueles com mais de 45 anos.

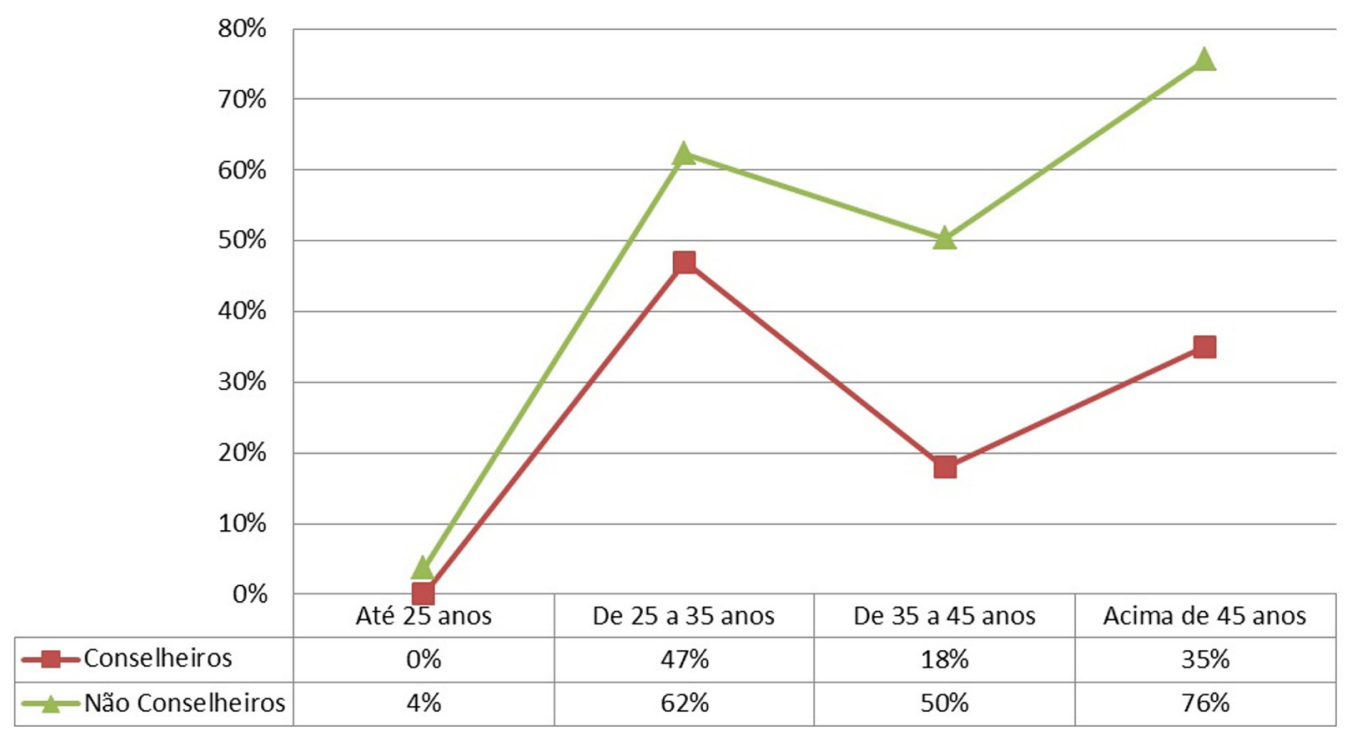

Figura 12.1 Não conselheiros conhecedores da Filosofia de Polícia Comunitária e conselheiros agrupados por faixa etária. Fonte: Elaboração do autor.

Inversos a esta tendência são os percentuais dos usuários de redes sociais digitais, em que os mais novos são a maioria em todos os grupos. 


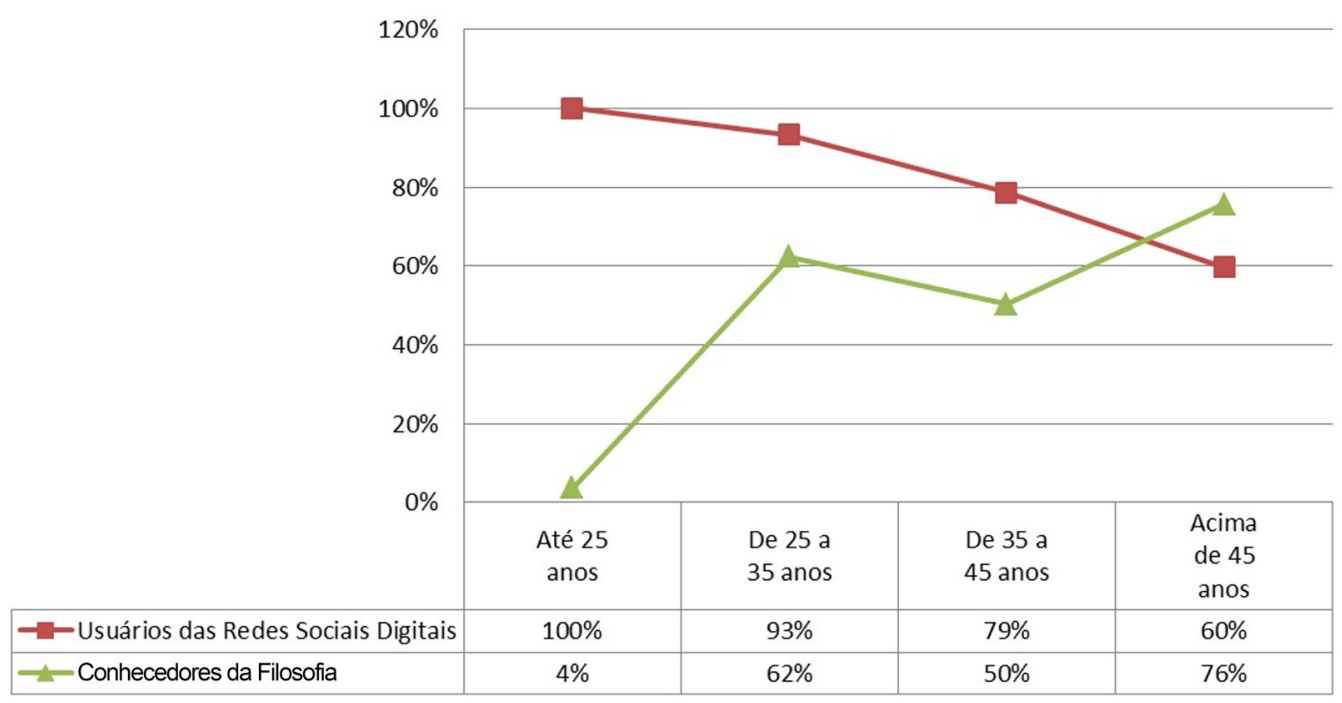

Figura 12.2 Comparativo do percentual dos usuários de redes sociais digitais e conhecedores da Filosofia de Polícia Comunitária por faixa etária.

Fonte: Elaboração do autor.

Mesmo entre os homens com idade acima de 45 anos, que são o grupo com maior percentual de conhecedores da Filosofia e dos Consegs, este percentual ainda é muito baixo, principalmente entre os pedestres. Os percentuais melhoram no grupo dos trabalhadores do comércio e continuam subindo no grupo dos diretores de escolas. Contudo, nem nestes últimos, que possuem dois anos de contato com a Filosofia de Polícia Comunitária, os jovens foram alcançados. A diferença de tempo de participação em projetos de polícia comunitária mostrou-se significativa, pois os trabalhadores do comércio apresentam percentuais de conhecedores de Filosofia e dos Consegs muito menores do que os dos diretores de escolas.

Filtrando os dados pelo gênero dos participantes, as tendências anteriores permanecem: os homens não conselheiros conhecedores da Filosofia e dos Consegs contam com percentual muito maior do que as mulheres do mesmo grupo, e a adesão às redes sociais digitais também segue sentido inverso, sendo as mulheres a maioria dos usuários.

O grupo dos diretores de escolas foi ignorado, na Figura 12.3, devido ao fato de que $86 \%$ dos seus participantes são do sexo feminino, o que inviabiliza o uso de tais dados em uma comparação entre sexos.

Enquanto a diferença entre homens e mulheres conhecedores da Filosofia de Polícia Comunitária e Consegs é de $9 \%$ a mais para os homens, a diferença entre os gêneros dos conselheiros é de $52 \%$ a mais para os homens. Pode-se deduzir, então, que a diferença entre os gêneros dos conselheiros não se assenta, isolada- 
mente, na capacidade de se fazer conhecer da Filosofia de Polícia Comunitária e dos Consegs.

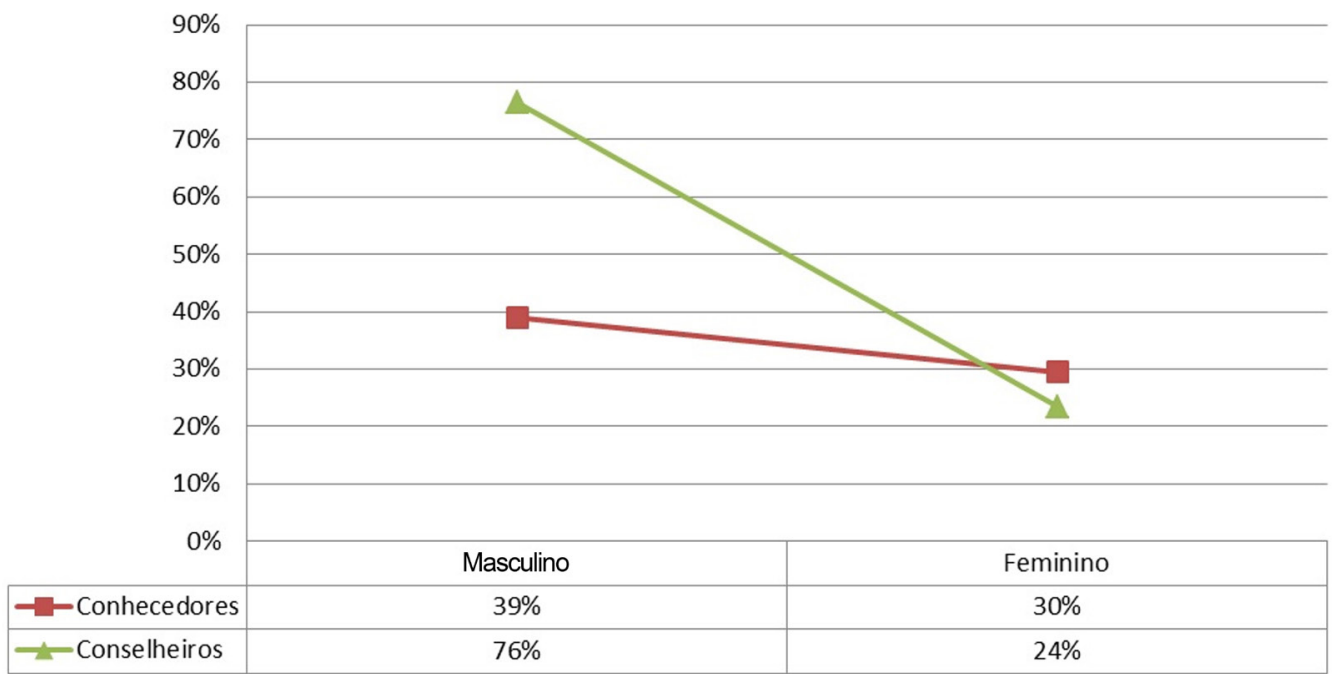

Figura 12.3 Não conselheiros conhecedores da Filosofia de Polícia Comunitária/Consegs e conselheiros agrupados por sexo.

Fonte: Elaboração do autor.

Por outro viés, resta claro que a capacidade de cooptar conselheiros dos Consegs está diretamente ligada à capacidade de difundir a Filosofia de Polícia Comunitária. Além disso, as redes sociais digitais apresentam-se como um campo fértil para difundir a filosofia e divulgar as ações dos Consegs, principalmente àqueles que são pouco ou nada representados nos conselhos: as mulheres e os jovens com menos de 25 anos.

A utilização das redes sociais digitais demonstra grande potencial para auxiliar na solução de quatro dos problemas dos Consegs: baixo número de conselheiros e representatividade, dificuldade de divulgar sua filosofia e ações, ausência de jovens e discrepância entre os gêneros.

Porém, a utilização das redes encontra severa resistência, inclusive figura entre os problemas inicialmente levantados. Para verificar suas possíveis causas, foram analisadas algumas questões: grau de instrução dos conselheiros, possibilidade de acesso à internet e adesão aos sites e aplicativos de redes sociais digitais pelos conselheiros.

Nenhuma das questões pesquisadas apresentou-se como causa para a não utilização das TIC pelos Consegs, especialmente dos sites e aplicativos de redes sociais digitais. O grau de instrução dos conselheiros é altíssimo para os padrões brasileiros $(70 \%$ possuem nível superior, sendo que $41 \%$ possuem no mínimo 
uma especialização, ou seja, os conselheiros provavelmente não possuem problemas em compreender e utilizar as TIC). Quanto ao acesso internet e a utilização de e-mail, os dados foram idênticos $(94 \%$ possuem acesso à internet e e-mail pessoal e a participação nas de redes sociais em meio digital é praticada por $88 \%$ dos conselheiros).

Entende-se, pelos dados expostos, que os Consegs, por meio de seus conselheiros, estão plenamente aptos à utilização das redes sociais digitais. Contudo, os sites e os aplicativos destinados a este fim são inúmeros e não seria prático participar de todos eles simultaneamente, em especialmente para os Consegs, pois seus conselheiros são voluntários e nada recebem por seus serviços. Por esta razão, foram pesquisados quais são os sites e os aplicativos mais utilizados entres os grupos do estudo.

घté 25 anos De 25 a 35 Anos De 35 a 45 anos $\square$ Acima de 45 anos

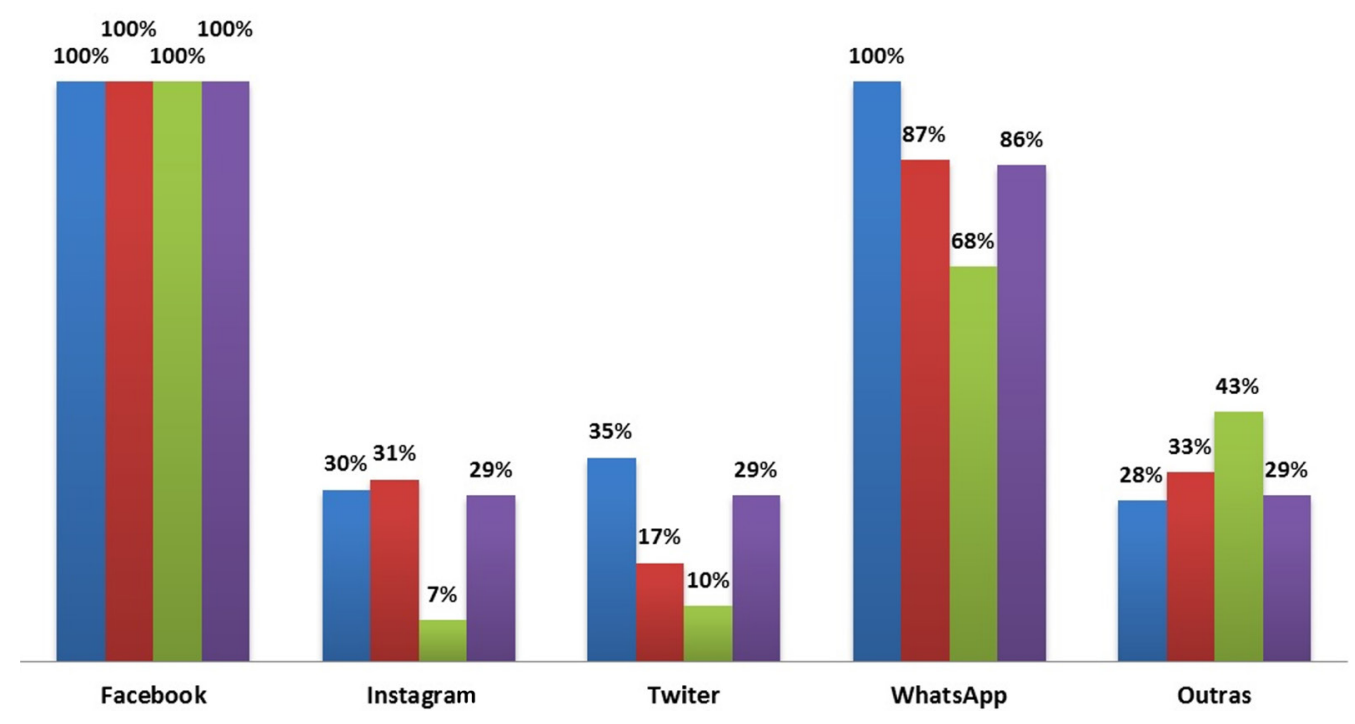

Figura 12.4 Principais sites e aplicativos de redes sociais acessados pelos grupos de não conselheiros por faixa etária.

Em todos os grupos, o Facebook e o WhatsApp são hegemônicos. Os jovens e as mulheres apresentam tendência a participar de mais de duas redes sociais digitais simultaneamente, mas, mesmo entre eles, a preferência permanece com o Facebook, com quase 100\% de adesão, seguindo do WhatsApp, com quase $90 \%$ de adeptos. 


\section{CONSIDERAÇÕES FINAIS}

Considerando o nível de instrução, possibilidade acesso à internet e participação em redes sociais dos conselheiros, pode-se afirmar que eles são plenamente aptos a utilizar as redes sociais digitais como ferramenta dos Consengs.

Tendo em vista que o Facebook e o Whatsapp são os sites/aplicativos de redes sociais digitais com maior número de adeptos na região do Vale do Araranguá, pode-se sugerir a utilização de ambos inicialmente. Considerando a dificuldade de manter os conselheiros ativos e participando das reuniões, sugere-se que as reuniões migrem para o meio digital ou, ao menos, partes delas.

Quanto ao problema do descrédito, de os conselheiros não verem os Consegs como um meio eficiente à Filosofia de Polícia Comunitária, deve-se deixar bem claro que tal descrédito não se estende à Filosofia, pois os entrevistados foram unânimes em afirmar que a Filosofia de Polícia Comunitária é um grande avanço rumo à democratização, eficiência e eficácia das polícias brasileiras.

Alguns pontos da pesquisa geraram dúvidas que suscitam maiores estudos, como a relação entre conhecer a Filosofia de Polícia Comunitária e participar dos Consegs, que se mostrou significativa; contudo, outros pontos necessitam de estudo. A diferença entre o número de participantes homens e mulheres não se explica, isoladamente, pelo fato dos homens terem o maior percentual de conhecedores da Filosofia de Polícia Comunitária. O reflexo de uma sociedade patriarcal, na qual o homem ainda é visto como o arrimo da família, poderia ser estudado como uma causa significativa da baixa representação feminina nos Consegs.

Por sua vez, os meios utilizados para difundir a Filosofia de Polícia Comunitária mostraram-se incapazes de alcançar os jovens com idades abaixo de 25 anos. Estudos da linguagem e meios usados pelos Consegs para divulgarem sua ideologia são imperiosos, pois a opinião dos jovens é importantíssima na construção democrática da segurança.

Sabe-se que a participação nos Consegs exige um mínimo de conhecimento. Um estudo sobre os impactos da formação dos conselheiros por EAD e MOOCs poderia sugerir melhorias consideráveis nesta área.

Outro ponto que merece um estudo mais aprofundado é a razão pela qual os Consegs mantiveram-se distantes das TIC, pois a presente pesquisa deixa claro que os conselhos, por meio dos seus conselheiros, são plenamente aptos a utilizarem as TIC, contudo não o fazem.

Ao final deste estudo, pode-se afirmar que os métodos ortodoxos de participação social, na era do conhecimento e da vida digital, não são ferramentas adequadas à transmissão de conhecimento e participação social democrática que a demanda da criminalidade exige para soluções adequadas preventivas e dura- 
douras. Estudos, para a utilização das TIC como ferramentas para sanar essas demandas são necessários e urgentes, caso contrário, viveremos um discurso de democracia participativa, maquiada com a oferta de ferramentas inválidas e inviáveis para real participação social na segurança pública.

\section{REFERÊNCIAS}

BOL NOTÍCIAS. Facebook tem 1,23 bilhão de usuários mundiais; 61,2 milhões são do Brasil. 3 fev. 2014. Disponível em: <http://noticias.bol.uol.com.br/ultimas-noticias/ tecnologia/2014/02/03/facebook-em-numeros.htm>. Acesso em: 21 dez. 2014.

BRASIL. Constituição da República Federativa do Brasil de 1988. Disponível em: $<$ http://www.planalto.gov.br/ccivil_03/constituicao/constitui\%C3\%A7ao.htm>. Acesso em: 20 nov. 2014.

. MINISTÉRIO DA JUSTIÇA. Redes sociais, mobilização e segurança pública: evolução da rede de atores da segurança pública no processo preparatório da $1^{\text {a }}$ Conferência Nacional de Segurança Pública. Coordenação Geral da $1^{a}$ Conferência Nacional de Segurança Pública. Ano I. Brasília, 2009.

CARVALHO, V. A.; SILVA, M. R. F. Política de segurança pública no Brasil: avanços, limites e desafios. Revista Katálysis, v. 14, n. 1, p. 59-67, jan. 2011.

COUTINHO, C. P.; JUNIOR, J. B. B. Blog e wiki: os futuros professores e as ferramentas da web 2.0. SIIE'2007, 14-16 nov. 2007, p. 199-204. ISBN 978-972-8969-04-2.

CRUZ, R. C. Redes sociais virtuais: premissas teóricas ao estudo em ciência da informação. TransInformação, Campinas, v. 22, n. 3, p. 255-272, set./dez. 2010.

ESTADO DE S.PAULO, O. Facebook chega a 1,35 bilhão de usuários no mundo. Link. 28 out. 2014. Disponível em: <http://blogs.estadao.com.br/link/facebook-chega-a-135bilhao-de-usuarios-no-mundo/>. Acesso em: $21 \mathrm{dez} .2014$.

FERNANDES, S. S. O Conselho Comunitário de Segurança de Forquilhinhas e a filosofia da polícia comunitária: um estudo de caso. Florianópolis, 2011. 128 p. Dissertação (Mestrado) - Universidade Federal de Santa Catarina - Centro de Filosofia e Ciências Humanas - Programa de Pós-Graduação em Sociologia Política. Florianópolis, 2011. HIPÓLITO, M. M.; TASCA, J. E. Superando o mito do espantalho: uma polícia orientada para a resolução dos problemas de segurança pública. Florianópolis: Insular, 2012.

MARCENEIRO, N. Implantação do gerenciamento pela qualidade total na polícia militar de Santa Catarina: um estudo de caso. 2001. 204 f. Dissertação (Mestrado em Engenharia de Produção) - Centro Tecnológico. Universidade Federal de Santa Catarina. Florianópolis, 2001.

Introdução ao estudo da segurança pública: livro didático. 3.ed. rev. e atual. Palhoça: Unisul Virtual, 2005.

Polícia comunitária: construindo segurança nas comunidades. Florianópolis: Insular, 2009. 
MARCENEIRO, N.; PACHECO, G. C. Polícia comunitária: evoluindo para a polícia do século XXI. Florianópolis: Insular, 2005.

MARTINS, R. D.; LOTTA, G. S. Capital social e redes sociais como alternativa para análise de políticas públicas de educação: o caso de Icapuí-CE. Aval. Pol. Públ. Educ. [online], v. 18, n. 69, p. 843-860, 2010.

MARTELETO, R. M. Análise de redes sociais: aplicação nos estudos de transferência da informação. Ci. Inf. [online], v.30, n.1, p. 71-81, 2001.

MATOS, M. G. R. Redes sociais e a polícia comunitária: estudo de caso dos CONSEGs do Vale do Araranguá. Monografia (especialização) - Universidade Federal de Santa Catarina - Campus Araranguá. Pós-graduação em Tecnologias da Informação e Comunicação Aplicadas à Segurança Pública e Direitos Humanos. Araranguá, 2015. 112 p.

RAUEN, F. J. Roteiros de investigação científica. Tubarão: Unisul, 2002.

RECUERO, R. Redes sociais na internet. Porto Alegre: Sulina, 2009.

SANTA CATARINA - SC. Regulamento dos Conselhos Comunitários de Segurança. 2001. Disponível em: <http://notes1.pm.sc.gov.br/ aplicacoes/policiacomunitaria.nsf>. Acesso em: 10 jan. 2015.

. Decreto no 2.136, de 12 de março de 2001. Autoriza criação de Conselhos Comunitários de Segurança e dá outras providências. Brasília, 2001.

SECRETARIA NACIONAL DE SEGURANÇA PÚBLICA - SENASP. Curso Nacional de Promotor de Polícia Comunitária. Grupo de Trabalho. Portaria SENASP nº 002/2007. Brasília: Senasp, 2007.

SOUZA, M. V.; SIMON, R. M. Redes sociais e MOOCs: análise de mídias para uma educação em rede. XI Congresso Brasileiro de Ensino a Distância. 2014. Florianópolis: Unirede, 5-8 ago. 2014, p. 313-327.

TRIVIÑOS, A. N. S. Introdução à pesquisa em ciências sociais: a pesquisa qualitativa em educação. São Paulo: Atlas, 1987. 
